\title{
Influência da disposição dos feixes de árvores em diferentes angulações na produtividade e custos de um sistema de árvores inteiras
}

\author{
Influence of tree bunching angles on the productivity and costs of a full \\ tree system
}

\section{Ricardo Hideaki Miyajima ${ }^{1 *}$, Pedro Caldas de Britto², Rodrigo Petrongari Tonin', Thais Maria Millani ${ }^{1}$ e Paulo Torres Fenner ${ }^{1}$}

\section{Resumo}

Este trabalho teve como objetivo avaliar a influência de diferentes angulações das disposições dos feixes de árvores, em relação ao tempo, produtividade e custos de um sistema de colheita de árvores inteiras, composto por um feller buncher e um skidder. Os feixes eram alocados a $45^{\circ}, 90^{\circ}, 135^{\circ}$ e $180^{\circ}$ em relação ao alinhamento do plantio no quais também representaram a angulação necessária para o giro do feller buncher na formação dos feixes. Por meio do estudo de tempos e movimentos foi monitorado o tempo produtivo e o tempo não produtivo de cada equipamento. Posteriormente, foram realizadas análises de regressão de modo a obter a estimativa da produtividade e os custos de cada operação. Os resultados demonstraram que o tempo produtivo do feller buncher foi influenciado pelas angulações trabalhadas e pelo número de árvores por ciclo de modo que o ângulo de $45^{\circ}$ foi o que apresentou a maior produtividade $\left(105,70 \mathrm{~m}^{3} \mathrm{~h}^{-1}\right) \mathrm{e}$ menores custos $\left(1,80 \mathrm{USD} \mathrm{m}^{-3}\right)$. Nenhuma evidencia significativa foi encontrada que comprove a influência da angulação dos feixes na produtividade do skidder. Todavia, a produtividade do skidder foi influenciada pela distância de arraste, pelo número de árvores por ciclo, e pela velocidade de operação, sendo estimada em $181,90 \mathrm{~m}^{3} \mathrm{~h}^{-1}$ com custo de 0,75 USD m $\mathrm{m}^{-3}$ quando operado a $5 \mathrm{~km} \mathrm{~h}^{-1}$ e em $216,50 \mathrm{~m}^{3} \mathrm{~h}^{-1}$ com custo de $0,63 \mathrm{USD} \mathrm{m}^{-3}$ quando a velocidade foi de $7 \mathrm{Km} \mathrm{h}^{-1}$.
\end{abstract}

Palavras-chave: colheita florestal, estudo de tempos e movimentos, feller buncher, skidder

\begin{abstract}
The objective of this work was to evaluate the influence of different angulations of the tree bunching on the time, productivity and costs of a full tree harvesting system composed by a feller-buncher and a skidder. The bunches were placed at $45^{\circ}, 90^{\circ}, 135^{\circ}$ and $180^{\circ}$ in relation to the alignment of the forest plantation in which they also represented the necessary angulation for the rotation of the feller-buncher for the formation of the bunches. A work time study was performed in order to obtain the productive time and consequently to estimate productivity and costs of each operation. The feller-buncher's productivity was influenced by the angulations worked and the number of trees per cycle. The feller-buncher presented higher productivities $\left(105.70 \mathrm{~m}^{3} \mathrm{~h}^{-1}\right)$ and lower costs $\left(1.80 \mathrm{USD} \mathrm{\textrm {m } ^ { - 3 }}\right)$ when operated at $45^{\circ}$. The skidder's productivity was not influenced by the different angulations of the tree bunching. However it was related with the skidding distance, number of trees per cycle, and speed. The skidder's productivity was estimated at $181.90 \mathrm{~m}^{3} \mathrm{~h}^{-1}$ with a cost of 0.75 USD m-3 when the skidder was operated at $5 \mathrm{~km} \mathrm{~h}^{-1}$ and $216.50 \mathrm{~m}^{3} \mathrm{~h}^{-1}$ with a cost of $0.63 \mathrm{USD} \mathrm{m} \mathrm{m}^{-3}$ when operated at $7 \mathrm{~km} \mathrm{~h}^{-1}$.
\end{abstract}

Keywords: forest harvesting, work time study, feller-buncher, skidder

\section{INTRODUÇÃO}

O setor de florestas plantadas representa uma das principais atividades econômicas no Brasil. É um setor que possui uma participação em torno de 1,0\% do produto interno bruto brasileiro (PIB) e crescimento anual aproximado de 3,0\% (IBA, 2016).

1. FCA - Faculdade de Ciências Agronômicas de Botucatu, Unesp - Universidade Estadual Paulista Júlio de Mesquita Filho. Botucatu, SP, Brasil.

2. Universidade de Freiburg. Freiburg, Alemanha.

*Autor correspondente: richidetoshimiyajima@hotmail.com 
Plantios florestais são caracterizados por alta produtividade e competitividade em que mesmo uma pequena redução nos custos pode resultar em ganhos significativos para as empresas florestais. Ganhos que são ainda mais visíveis nas atividades de colheita florestal mecanizada nas quais respondem por aproximadamente 50\% dos custos totais de produção florestal (MACHADO, 2014). Concomitantemente, nas atividades que envolvem a colheita de madeira, a busca de melhorias com objetivo de atingir maior produtividade, melhor planejamento, redução de custos e competitividade no mercado é cada vez mais recorrente (FIEDLER et al., 2008; SANTOS et al., 2013a; SIMÕES et al., 2010a).

Existem diversos fatores que influenciam na produtividade e nos custos da colheita florestal (MACHADO, 2014; MALINOVSKI; MALINOVSKI, 1998). Dentre os quais é importante destacar: o objetivo do plantio florestal, tipo de floresta, espécie, espaçamento, distância de extração, topografia do terreno, tipo de solo, rendimento volumétrico do plantio, tratos silviculturais, clima, mão de obra e equipamentos disponíveis (BRAMUCCI; SEIXAS 2002; OLIVEIRA et al., 2009; SANTOS et al., 2013a).

Com a abertura das importações a partir da década de 90, foram disponibilizados no Brasil modernos equipamentos de colheita florestal e que possibilitaram importantes melhorias para o setor (MACHADO, 2014). Por meio deste significativo incremento de tecnologia disponível no mercado, o sistema de árvores inteiras tornou-se uma das principais opções para as empresas que buscavam alta produtividade e redução dos custos de operação. Este sistema de colheita é comumente utilizado em uma combinação entre o trator florestal feller buncher, que possuí capacidade de cortar e acumular várias árvores por ciclo operacional e do trator florestal skidder, que possuí capacidade de realizar a extração (arraste) de um grande número de árvores por viagem.

Nos últimos anos, diversos estudos avaliaram os aspectos técnicos e econômicos do sistema de árvores inteiras (feller buncher e skidder) em relação a diversas variáveis, tais como: distância de extração, declividade do terreno, tipos de máquina e seus rodados, diferentes produtividades de plantios e espécies (ANAYA; CRISTHIANSEN, 1986; FIEDLER et al., 2008; LOPES et al., 2014; ROCHA et al., 2009; SANTOS et al., 2013a). Entretanto, poucos trabalhos relacionaram a disposição e angulação dos feixes de árvores no interior do talhão na produtividade e custos desse sistema. Dentre os quais é possível destacar o trabalho de Nascimento et al. (2011) que avaliaram a influência de dois ângulos de derrubada na operação do feller buncher, no entanto, sem abranger a influência de outras variáveis e sem considerar o arraste que foi influenciado com resultado da operação do feller buncher.

Diante deste contexto e visando contribuir com a atual bibliografia relacionada ao desenvolvimento das operações no sistema de árvores inteiras, o presente trabalho teve como objetivo avaliar a influência de diferentes disposições e angulação dos feixes de árvore no interior do talhão sobre o tempo, produtividade e custos do feller buncher e do skidder.

\section{MATERIAL E MÉTODOS}

\section{Área de estudo}

A pesquisa foi realizada em uma empresa florestal localizada no município de Estrela do Sul, interior do Estado de Minas Gerais ( $18^{\circ} 58^{\prime}$ S; 47 $36^{\prime} \mathrm{O}$ ). O clima da região é tropical com estação seca bem definida (ALVARES et al., 2014). A pluviosidade média anual é de $1.500 \mathrm{~mm}$ e a temperatura média anual de $21,9^{\circ} \mathrm{C}$. A coleta de dados foi realizada somente em dias sem chuvas e com uma temperatura média de $23^{\circ} \mathrm{C}$. O solo da região foi classificado em latossolo vermelho amarelo, com um relevo plano e declives inferiores a 3\% (SANTOS et al., 2013b).

A empresa possui aproximadamente 275 mil ha com plantio de Eucalyptus sp. Para este estudo foram selecionadas duas faixas de terreno homogêneas e planas nas quais cada faixa possuía 76,80 m de largura (24 linhas de plantio) e $500 \mathrm{~m}$ de comprimento, totalizando uma área total de pesquisa de 7,60 ha. Todavia, é importante ressaltar que nas avaliações do feller buncher considerou-se apenas metade da área total selecionada para o estudo (3,80 ha). Como o feller buncher trabalhava com um número menor de árvores por ciclo operacional, quando comparado com o skidder, foi possível observar um número maior de repetições por unidade de área, possibilitando a redução da área amostrada.

O estudo foi conduzido em um povoamento clonal de Eucalyptus sp. com 11 anos de idade, em primeira rotação e que tinha como objetivo fornecer matéria prima para uma indústria de painéis de madeira. O espaçamento do plantio era de 3,20 m por 2,80 m. Por meio do inventário pré-colheita, realizado pelos autores, foram identificados o diâmetro a altura do peito (DAP) médio de $18,30 \mathrm{~cm}$ 
e a altura média das árvores de 28,10 m. O volume médio individual por árvore (VMI) foi estimado em $0,38 \mathrm{~m}^{3}$ arv $^{1}$.

\section{Descrição do sistema de colheita}

Foi avaliado o sistema de colheita de árvores inteiras (MACHADO, 2014) na qual o corte era realizado por um feller buncher da marca John Deere, modelo 903 J e o arraste por um skidder da marca Tigercat, modelo 635 D. O feller buncher (Figura 1a) possuía um motor com potência de $216 \mathrm{~kW}$, rodados de esteira e um braço hidráulico com alcance de $8,40 \mathrm{~m}$. Sua massa aproximada era de 30 te o cabeçote possuía uma capacidade de acúmulo de árvores de 0,52 $\mathrm{m}^{2}$. O feller buncher trabalhava em faixas de terreno de $12 \mathrm{~m}$ (a cada 4 linhas de plantio) realizando o corte e acúmulo de 3 a 6 árvores por ciclo de derrubada. Após o corte e acúmulo das árvores no cabeçote, o feller buncher depositava as árvores no chão formando os feixes de árvores para a posterior operação de arraste. Geralmente cada feixe de árvores era formado com 2 ciclos do feller buncher, sendo composto de 6 a 12 árvores.

O skidder (Figura 1b) possuía um motor com potência de $191 \mathrm{~kW}$, articulado e com tração 6x6. Sua massa aproximada era de 21 t e a pinça traseira possuía uma área útil de carga de 2,32 $\mathrm{m}^{2}$. O skidder realizava o arraste das árvores do interior do talhão para o estaleiro localizado na beira da estrada. Geralmente o skidder acumulava e carregava de dois a três feixes de madeira previamente formados pelo feller buncher sendo, desta forma, arrastado de 15 a 30 árvores por viagem.
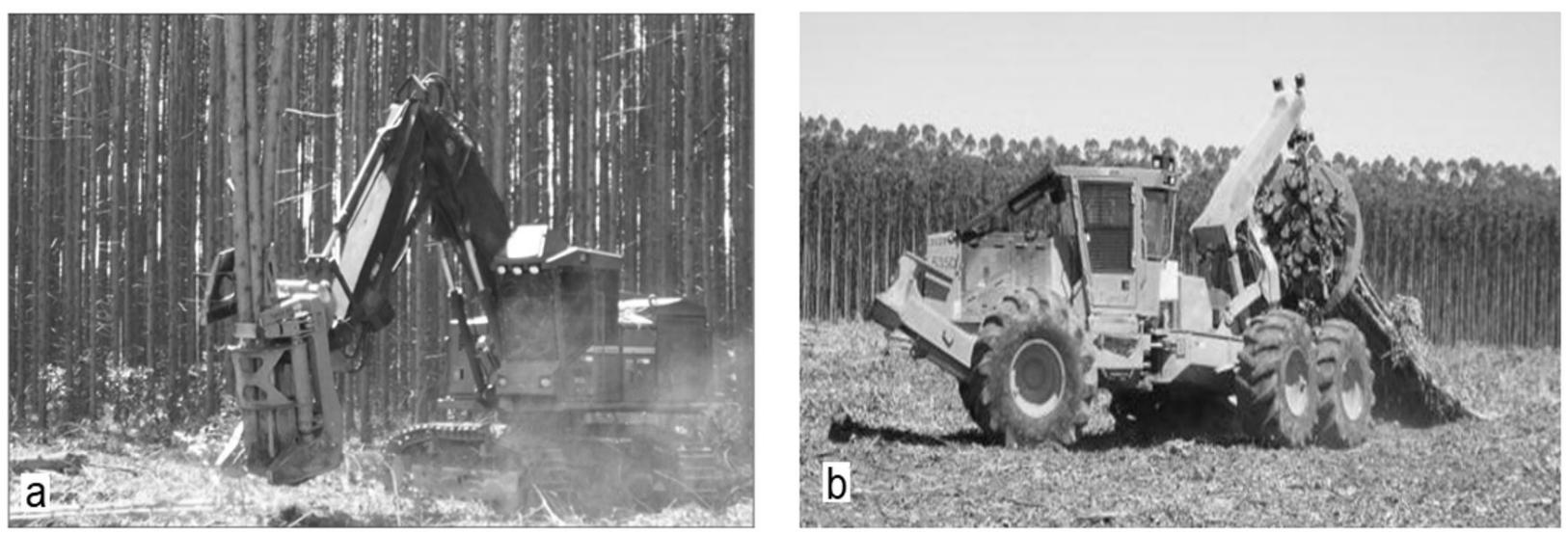

Figura 1. a) Feller buncher, John Deere $903 \mathrm{~J}$; b) Skidder,Tigercat $635 \mathrm{D}$

Figure 1. a) Feller buncher, John Deere $903 \mathrm{~J}$; b)Skidder, Tigercat $635 \mathrm{D}$

\section{Disposição dos feixes de árvores}

Foram avaliadas quatro diferentes disposições dos feixes de árvores no interior do talhão (DI, DII, DIII e DIV). As disposições foram classificadas de acordo com a angulação em que o feller buncher depositava os feixes após o processo de corte (Tabela 1). Cada eito de trabalho possuía $500 \mathrm{~m}$ de comprimento e como o talhão era localizado entre duas estradas (estrada A e B), foi possível realizar o arraste das árvores para ambos os lados. Fato que resultou em uma distância máxima de arraste de $250 \mathrm{~m}$ e a distância média de 125 m (Figura 2).

Tabela 1. Posicionamento dos feixes de acordo com as disposições avaliadas

Table 1. Positioning of tree bunches according to the evaluated layout

\begin{tabular}{ccccc}
\hline Disposição & $\begin{array}{c}\text { Ângulo do feixe em } \\
\text { relação à estrada }\end{array}$ & $\begin{array}{c}\text { Ângulo do feixe } \\
\text { em relação ao } \\
\text { alinhamento do } \\
\text { plantio }\end{array}$ & $\begin{array}{c}\text { Ângulo de operação } \\
\text { do feller buncher }\end{array}$ & $\begin{array}{c}\text { Distância de arraste } \\
\text { do skidder }\end{array}$ \\
\hline DI & $90^{\circ}$ & $0^{\circ}$ & $180^{\circ}$ & $5 \mathrm{~m}-30 \mathrm{~m}$ \\
DII & $0^{\circ}$ & $90^{\circ}$ & $90^{\circ}$ & $50 \mathrm{~m}-250 \mathrm{~m}$ \\
DIII & $45^{\circ}$ & $45^{\circ}$ & $45^{\circ}$ & $30 \mathrm{~m}-250 \mathrm{~m}$ \\
DIV & $45^{\circ}$ & $315^{\circ}$ & $135^{\circ}$ & $30 \mathrm{~m}-250 \mathrm{~m}$ \\
\hline
\end{tabular}


D I
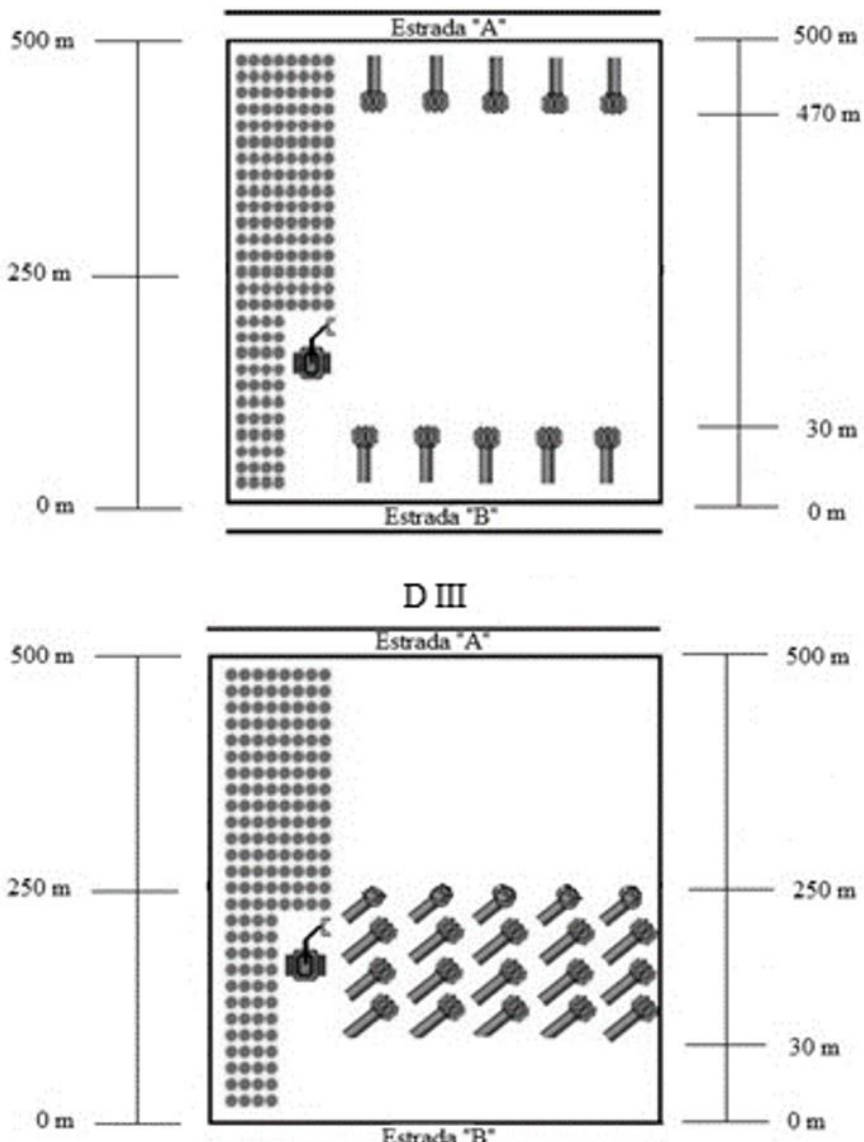

D III
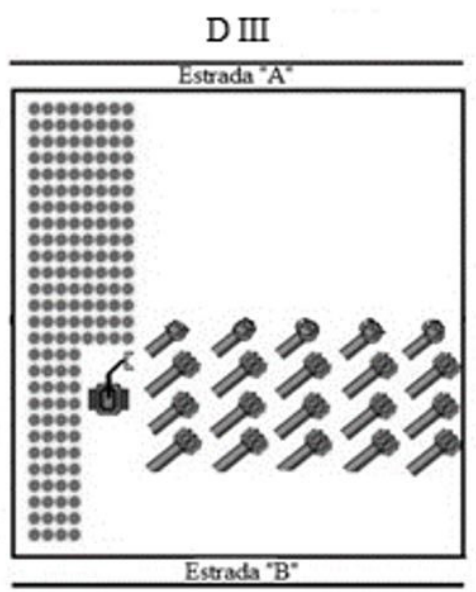

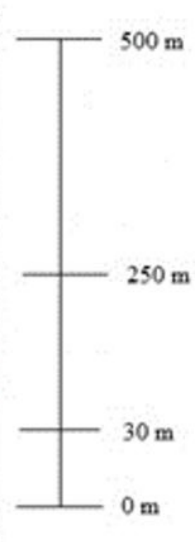

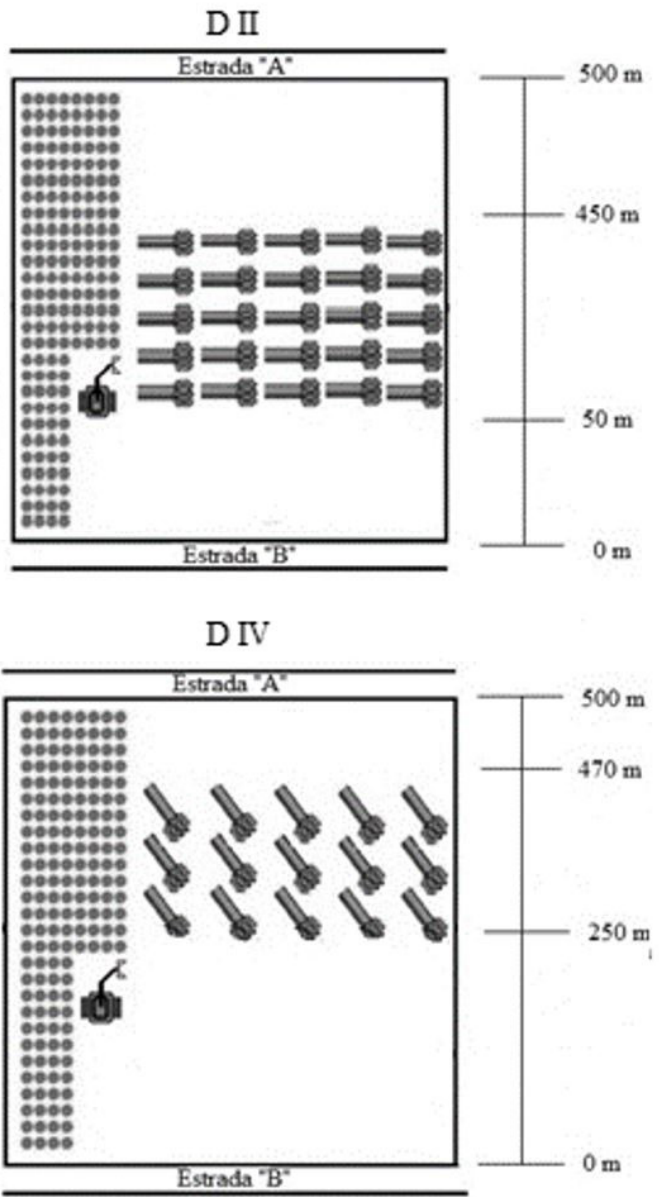

Figura 2: Disposição dos feixes no interior do talhão

Figure 2. Layout of tree bunches inside the stand

A DI foi caracterizada pela alocação dos feixes de árvores de $90^{\circ}$ em relação à estrada e paralelos ao alinhamento do plantio. Essa disposição ocorreu somente nos primeiros $30 \mathrm{~m}$ do talhão a partir da estrada (12 fileiras de plantio). Foi necessária e utilizada para abertura de espaço no começo das faixas de trabalho do feller buncher. Nessa disposição o feller buncher realizava um giro de $180^{\circ}$ com a cabine e depositava os feixes na região oposta ao seu sentido de deslocamento. O skidder por sua vez, realizava viagens curtas e geralmente com apenas um único feixe de árvores por ciclo (de 6 a 12 árvores).

Na DII os feixes de árvores eram alocados paralelos à estrada e com uma angulação de $90^{\circ} \mathrm{em}$ relação ao alinhamento do plantio. Foi uma disposição avaliada entre $50 \mathrm{~m} \mathrm{e} 450 \mathrm{~m}$ do talhão. Nessa disposição o feller buncher realizava um giro de $90^{\circ}$ para deposição dos feixes no interior do talhão. Na DII o skidder acumulava de dois a três feixes por viagem e os feixes localizados de $50 \mathrm{~m}$ até $250 \mathrm{~m}$ de talhão eram arrastados pelo skidder até a estrada " $\mathrm{B}$ " e os feixes localizados de $250 \mathrm{~m}$ até $450 \mathrm{~m}$ de talhão eram arrastados até a estrada " $\mathrm{A}$ ".

A DIII foi caracterizada pela alocação dos feixes a $45^{\circ}$ em relação à estrada "B" sendo que estes também apresentavam $45^{\circ}$ em relação ao alinhamento do plantio. Nessa disposição o feller buncher trabalhava com um giro de $45^{\circ}$. Foi uma disposição avaliada entre $30 \mathrm{~m}$ e $250 \mathrm{~m}$ de talhão. A DIII representa o trabalho realizado na primeira metade do talhão na qual as árvores eram direcionadas para o arraste à estrada "B". Sempre que o feller buncher iniciava um eito com a DIII, necessariamente a segunda metade do talhão (entre $250 \mathrm{~m} \mathrm{e} 470 \mathrm{~m}$ ) era realizada a DIV de modo a direcionar o arraste para ambas as estradas. Na DIV os feixes eram alocados a $45^{\circ}$ em relação à estrada "A" e apresentavam $135^{\circ} \mathrm{em}$ relação ao alinhamento do plantio. Nessa disposição o feller buncher realizava um giro de $135^{\circ}$ para formar os feixes. Tanto na DIII quanto na DIV o skidder acumulava de dois a três feixes por viagem. Na DIII o skidder realizava o arraste até a estrada "B" e na DIV o skidder realizava o arraste até a estrada "A". 


\section{Coleta de dados e análise estatística}

Em ordem de avaliar o trabalho do feller buncher e do skidder foi realizado o estudo de tempos e movimentos seguindo a metodologia de tempo contínuo (MAGAGNOTTI; SPINELLI 2012). O tempo das atividades foi cronometrado e registrado com um cronometro de resolução centesimal e planilhas de campo. O tempo observado da atividade foi dividido em (1) tempo produtivo e (2) tempo não produtivo (BJORHENDEN; THOMPSON, 2000). As atividades realizadas durante o tempo produtivo (1) foram subdivididas e classificadas em elementos do ciclo operacional conforme descritos na Tabela 2. O tempo não produtivo (2) foi classificado em: (2a) Manutenção e abastecimento (MA); (2b) Descanso e paradas do operador (PO); (2c) Deslocamento (DE); e (2d) Trabalho complementar (TC).

Tabela 2. Descrição dos elementos do ciclo operacional do feller buncher e do skidder

Table 2. Description of the elements of the feller-buncher and skidder operating cycle

\begin{tabular}{|c|c|c|}
\hline & Elementos do ciclo & Descrição \\
\hline \multirow[t]{2}{*}{$\begin{array}{l}\text { (1a) } \\
\text { Feller buncher }\end{array}$} & Busca e Corte & $\begin{array}{l}\text { Do momento em que o cabeçote inicia o movimento para o corte da } \\
\text { primeira árvore do ciclo até o momento em que o cabeçote finaliza o } \\
\text { corte e inicia o movimento para liberar as árvores nos feixes. }\end{array}$ \\
\hline & Basculada & $\begin{array}{l}\text { Do momento em que o cabeçote finaliza o corte e inicia o movimento } \\
\text { para liberar as árvores nos feixes até o momento em que o cabeçote } \\
\text { inicia o movimento para o corte da primeira árvore do ciclo. }\end{array}$ \\
\hline \multirow[t]{4}{*}{$\begin{array}{l}\text { (1b) } \\
\text { Skidder }\end{array}$} & Viagem vazia & $\begin{array}{l}\text { Do momento em que o skidder fecha a garra vazia e inicia o } \\
\text { deslocamento em direção ao interior do talhão até o momento que o } \\
\text { skidder inicia abertura da garra para carga do primeiro feixe. }\end{array}$ \\
\hline & Carga & $\begin{array}{l}\text { Do momento que o skidder inicia abertura da garra para carga do } \\
\text { primeiro feixe até o momento em que o skidder fecha a garra após } \\
\text { carga do último feixe e inicia o deslocamento até a beira do talhão. }\end{array}$ \\
\hline & Viagem carregada & $\begin{array}{l}\text { Do momento em que o skidder fecha a garra após carga do último } \\
\text { feixe e inicia o deslocamento até a beira do talhão até o momento } \\
\text { em que o skidder, já na beira do talhão, inicia abertura da garra para } \\
\text { formar o estaleiro. }\end{array}$ \\
\hline & Descarga & $\begin{array}{l}\text { Do momento em que o skidder, já na beira do talhão, inicia abertura da } \\
\text { garra para formar o estaleiro até o momento em que o skidder fecha a } \\
\text { garra vazia e inicia o deslocamento em direção ao interior do talhão. }\end{array}$ \\
\hline
\end{tabular}

A distância de arraste foi previamente medida com auxílio de uma trena e demarcada no campo com estacas de madeira, posicionadas a cada $50 \mathrm{~m}$. Durante o processo de colheita foi observado e registrado o número de árvores em cada ciclo operacional, tanto para o feller buncher quanto para o skidder. Também foi monitorada a velocidade média de deslocamento do skidder. Para esse fim, foi previamente determinada uma parte do eito em que o operador do skidder realizaria a operação a $5 \mathrm{~km} \mathrm{~h} 1$ e outra parte do eito em que o operador realizaria a operação a $7 \mathrm{~km} \mathrm{~h} \mathrm{~h}^{-1}$. A eficiência operacional foi calculada pela razão entre o tempo produtivo e o tempo total programado (horas programadas por turno) para o trabalho.

Por meio de um estudo piloto foi determinado o número mínimo de ciclos operacionais necessários seguindo o cálculo da intensidade amostral (FIEDLER et al., 2008; OLIVEIRA JUNIOR et al.,2009; SIMÕES et al., 2014, 2010a,b).

De modo a verificar diferenças estatísticas significativas $(\mathrm{p}<0,05)$ entre as quatro disposições avaliadas (DI, DII, DIII e DIV), foram realizadas análises de variância seguidas do teste "Tukey" de comparação de médias. Para tal utilizou-se o software SPSS versão 22.0 (IBM Corp. Armonk/NY; USA). As análises estatísticas foram executadas considerando o tempo produtivo total e o tempo de cada elemento do ciclo operacional, tanto para o feller buncher quanto para o skidder.

Posteriormente, o tempo produtivo do ciclo operacional do feller buncher e do skidder foram modelados por meio de uma regressão linear (método stepwise) e das suas variáveis independentes, também com auxílio do software SPSS (IBM Corp. Armonk/NY; USA). O tempo produtivo do feller buncher foi modelado em dependência do ângulo de giro da máquina e do número de árvores por ciclo. O tempo produtivo do skidder foi modelado em relação à distância de extração, do número de árvores por viagem e da velocidade de operação. 
Miyajima et al. - Influência da disposição dos feixes de árvores em diferentes

angulações na produtividade e custos de um sistema de árvores inteiras

\section{Estimativas dos Custos}

Os custos operacionais, foram estimados de acordo com a metodologia proposta por Ackerman et al. (2014). Os valores das máquinas e do tempo de vida útil foram obtidos por meio de pesquisa com revendedores de máquinas florestais e com informações fornecidas pela própria empresa. Os valores obtidos foram divididos em custos fixos e custos variáveis e estimados de acordo com o custo horário $\left(\mathrm{USD} \mathrm{h}^{-1}\right.$ ) e custos de produção (USD m³ ${ }^{-3}$ de cada equipamento (Tabela 3 ).

Tabela 3. Cálculo dos custos para o feller buncher e skidder

Table 3. Cost calculation for the feller-buncher and skidder

\begin{tabular}{|c|c|c|}
\hline Itens de custo & Feller buncher & Skidder \\
\hline Investimento (USD) & $558.355,72$ & $295.777,62$ \\
\hline Taxa de retorno (\%) & 10,00 & 10,00 \\
\hline Vida útil (horas) & $25.000,00$ & $25.000,00$ \\
\hline Tempo de utilização ao ano (horas) & $5.000,00$ & $5.000,00$ \\
\hline Depreciação (USD ano-1) & $98.413,54$ & $52.132,58$ \\
\hline Taxa (USD ano-1) & $35.630,24$ & $18.874,40$ \\
\hline Combustível (USD hora-1) & 44,10 & 33,60 \\
\hline Lubrificantes (USD hora-1) & 4,41 & 3,36 \\
\hline Manutenção (USD hora ${ }^{-1}$ ) & 22,33 & 11,83 \\
\hline Salário do operador (USD hora-1) & 51,17 & 51,17 \\
\hline Custo total (USD hora-1) & 188,60 & 136,97 \\
\hline
\end{tabular}

\section{RESULTADOS E DISCUSSÃO}

No total $32 \mathrm{~h}$ de trabalho foram monitoradas, dentro das quais o feller buncher executou 9,23 h produtivas, com um total de 827 ciclos observados e uma produção de $1.555 \mathrm{~m}^{3}$. Enquanto que o skidder executou 18,56 h produtivas, com um total de 340 ciclos observados e uma produção total de $3.800 \mathrm{~m}^{3}$. Cabe ressaltar que a área considerada na avaliação do feller (3,84 ha) foi apenas a metade da área considerada na avaliação do skidder (7,68 ha) explicando desta forma, a diferença encontrada no número de horas produtivas e a diferença da produção total entre o feller buncher e o skidder. Todavia, essa diferença não interferiu nos resultados deste trabalho, uma vez que o tempo produtivo de cada máquina foi avaliado individualmente.

A eficiência operacional calculada foi de $84 \%$ para o feller buncher e de $87 \%$ para o skidder. Valores que estão acima dos observados tanto por Fiedler et al. (2008) e Pereira et al. (2015) que descrevem, respectivamente, uma eficiência operacional de 35\% e 70\% para ofeller buncher, quanto por Fiedler et al. (2008) e Pereira et al. (2015) que descrevem, respectivamente, uma eficiência de 73\% e 58\% para o skidder. Neste caso é importante destacar que a coleta de dados ocorreu somente em dias sem chuva e que nenhuma grande interrupção por motivos de problema mecânico foi observada durante este período, fato que possivelmente superestima a eficiência operacional observada das máquinas. Visando obter um valor mais representativo do tempo não produtivo das máquinas seria recomendável um período maior de monitoramento dos equipamentos avaliados.

Por outro lado, considerando apenas o tempo produtivo das máquinas, o número de ciclos operacionais observados ( 827 do feller buncher e 340 do skidder) foi consideravelmente superior ao número mínimo de ciclos necessários conforme o cálculo da intensidade amostral que indicou um mínimo de 30 ciclos para o feller buncher e 50 ciclos para o skidder.

\section{Influência da disposição dos feixes de árvores no tempo produtivo do feller buncher e do skidder}

Os resultados da análise estatística do feller buncher e do skidder em relação às disposições dos feixes, são descritos na Tabela 4. Nas avaliações do skidder os dados da DIV foram incluídos e analisados juntamente com a DIII, uma vez que considerando apenas o arraste ambas apresentam as mesmas características em termos de angulação dos feixes, número de árvores por ciclo, e distância de arraste.

A DI foi à única disposição que apresentou diferença estatística significativa $(\mathrm{p}<0,05)$ no tempo total do ciclo operacional tanto para o feller buncher quanto para o skidder. Nesta disposição o feller buncher, demandou um maior tempo para completar o ciclo operacional $\left(0,68\right.$ min ciclo $\left.{ }^{-1}\right)$ quando 
Tabela 4. Estatística descritiva do tempo total do feller buncher e do skidder e tempo dos elementos do ciclo com o número de observações e a média.

Table 4. Descriptive statistics of the total time of feller-buncher and skidder and time of the elements of the cycle with the number of observations and the average.

\begin{tabular}{|c|c|c|c|c|c|c|c|c|c|}
\hline \multirow{2}{*}{$\begin{array}{c}\text { Equipamento } \\
\text { Avaliado }\end{array}$} & \multirow{2}{*}{ Elemento do ciclo } & \multicolumn{2}{|c|}{ Disposição I } & \multicolumn{2}{|c|}{ Disposição II } & \multicolumn{2}{|c|}{ Disposição III } & \multicolumn{2}{|c|}{ Disposição IV * } \\
\hline & & $\mathbf{N}$ & Média & $\mathbf{N}$ & Média & $\mathbf{N}$ & Média & $\mathbf{N}$ & Média \\
\hline \multirow[t]{4}{*}{ Feller buncher } & Tempo Total (min) & 84 & $0,68 \mathrm{~b}$ & 316 & $0,63 a$ & 230 & $0,61 \mathrm{a}$ & 198 & $0,61 \mathrm{a}$ \\
\hline & Busca e Corte & 84 & $0,49 b$ & 316 & $0,47 \mathrm{~b}$ & 230 & $0,43 a$ & 198 & $0,44 \mathrm{a}$ \\
\hline & Basculada & 84 & $0,19 a$ & 316 & $0,16 \mathrm{a}$ & 230 & $0,18 a$ & 198 & $0,17 \mathrm{a}$ \\
\hline & Árvores por ciclo (n) & 84 & $4,55 \mathrm{~b}$ & 316 & $5,00 a$ & 291 & $4,94 a$ & 198 & $5,00 \mathrm{a}$ \\
\hline \multirow[t]{8}{*}{ Skidder } & Tempo Total (min) & 31 & $0,79 a$ & 170 & $3,53 \mathrm{~b}$ & 139 & $3,50 \mathrm{~b}$ & * & * \\
\hline & Viagem Vazia & 31 & $0,29 a$ & 170 & $1,14 b$ & 139 & $1,10 \mathrm{~b}$ & * & * \\
\hline & Carga & 31 & $0,26 a$ & 170 & $1,15 b$ & 139 & $1,24 b$ & * & * \\
\hline & Viagem Carregada & 31 & $0,17 \mathrm{a}$ & 170 & $1,16 b$ & 139 & $1,05 \mathrm{~b}$ & * & * \\
\hline & Descarga & 31 & $0,07 \mathrm{a}$ & 170 & $0,08 a$ & 139 & $0,11 \mathrm{a}$ & * & * \\
\hline & $\mathrm{N}$ de árvores $(\mathrm{n})$ & 31 & $14,06 \mathrm{~b}$ & 170 & $31,48 \mathrm{a}$ & 139 & $30,32 \mathrm{a}$ & * & * \\
\hline & Distância (m) & 31 & $25,00 \mathrm{a}$ & 170 & $114,41 b$ & 139 & $114,93 b$ & * & * \\
\hline & Velocidade $\left(\mathrm{Km} \mathrm{h}^{-1}\right)$ & 31 & $5,77 \mathrm{a}$ & 170 & $5,71 \mathrm{a}$ & 139 & $5,95 a$ & * & * \\
\hline
\end{tabular}

comparado com as disposições DII (0,63 min ciclo $\left.{ }^{-1}\right)$, DIII (0,61 min ciclo $\left.{ }^{-1}\right)$ e DIV $\left(0,61\right.$ min ciclo $\left.^{-1}\right)$. Enquanto que o tempo observado por ciclo operacional do skidder foi significativamente $(\mathrm{p}<0,05)$ menor $\left(0,79 \mathrm{~min}\right.$ ciclo $\left.^{-1}\right)$ do que quando comparado com as disposições DII $\left(3,53 \mathrm{~min} \mathrm{ciclo}^{-1}\right) \mathrm{e}$ DIII (3,50 min ciclo $\left.^{-1}\right)$.

Todavia, cabe ressaltar que a DI ocorreu somente nos primeiros $30 \mathrm{~m}$ de talhão e foi uma atividade necessária para a "abertura do eito" e da qual representou apenas $12 \%$ do volume total de madeira retirado por eito de trabalho. O maior tempo demandado pelo feller buncher pode ser justificado tanto pela dificuldade de trabalho nesta faixa de terreno, devido ao pouco espaço disponível para deposição dos feixes, quanto pelo maior giro do cabeçote $\left(180^{\circ}\right)$ necessário à formação dos feixes.

Por outro lado, quando observado o trabalho do skidder na DI, o menor tempo total demandado pode ser justificado devido a curta distância de extração percorrida (30 m). Entretanto, como o skidder trabalhava na DI com apenas um feixe por viagem (de 6 a 12 árvores), o menor volume transportado por ciclo não permitiu uma comparação direta com a produtividade da DII e da DIII. Lopes e Diniz (2015) também reiteraram a importância de considerar esses fatores nas avaliações de tempo e de produtividade do skidder.

Desta forma, considerando apenas a DII, DIII e DIV*, com resultados obtidos no interior do talhão e que representam $88 \%$ do volume produzido, não foram encontradas evidencias significativas $(\mathrm{p}<0,05)$ de que a variação da angulação dos feixes possa influenciar no tempo total produtivo tanto da derrubada quanto da extração, dentro das condições estudadas. Fato que também foi observado por Nascimento et al. (2011) avaliando a operação de derrubada do feller buncher nas angulações $45^{\circ}$ e $90^{\circ}$ em relação ao alinhamento de plantio.

Quando analisado individualmente os elementos do ciclo operacional do feller buncher (Figura 3a) foi possível notar que o elemento de "busca e corte" representou a maior proporção do tempo produtivo em todas as disposições (71\% na DI; 75\% na DII; $69 \%$ na DIII e 72\% na DIV). Fato que também foi descrito por Nascimento et al. (2011) e Simões et al. (2010a), avaliando o ciclo operacional do feller buncher em colheita de eucaliptos. Além disso, o tempo gasto com o elemento de "busca e corte" foi significativamente maior $(\mathrm{p}<0,05)$ nas disposições DI $\left(0,49 \mathrm{~min} \mathrm{ciclo}^{-1}\right)$ e DII $\left(0,47 \mathrm{~min} \mathrm{ciclo}^{-1}\right)$ quando comparado com as disposições DIII $\left(0,43 \mathrm{~min}_{\text {ciclo }}^{-1}\right)$ e DIV $\left(0,44 \mathrm{~min} \mathrm{ciclo}^{-1}\right)$. O que pode indicar uma tendência no aumento do tempo deste elemento conforme aumenta o ângulo de giro do cabeçote, uma vez que o maior tempo foi observado quando o feller buncher realizava um giro de $180^{\circ}$ (DI) e o menor tempo observado quando o feller buncher realizava um giro de $45^{\circ}$ (DIII). Já para o movimento de "basculada", nenhuma diferença estatística significativa foi encontrada entre as disposições avaliadas. O elemento "basculada" representou, respectivamente, 29\%, 25\%, 31\% e $28 \%$ do tempo produtivo nas DI, DII, DIII e DIV.

Considerando os elementos do ciclo operacional do skidder, o elemento "carga" apresentou o maior percentual do tempo produtivo na DII (33\%) e na DIII (35\%). O mesmo foi constado por Fernandes et al. (2009) que avaliaram a produtividade de um skidder em uma floresta de eucaliptos 

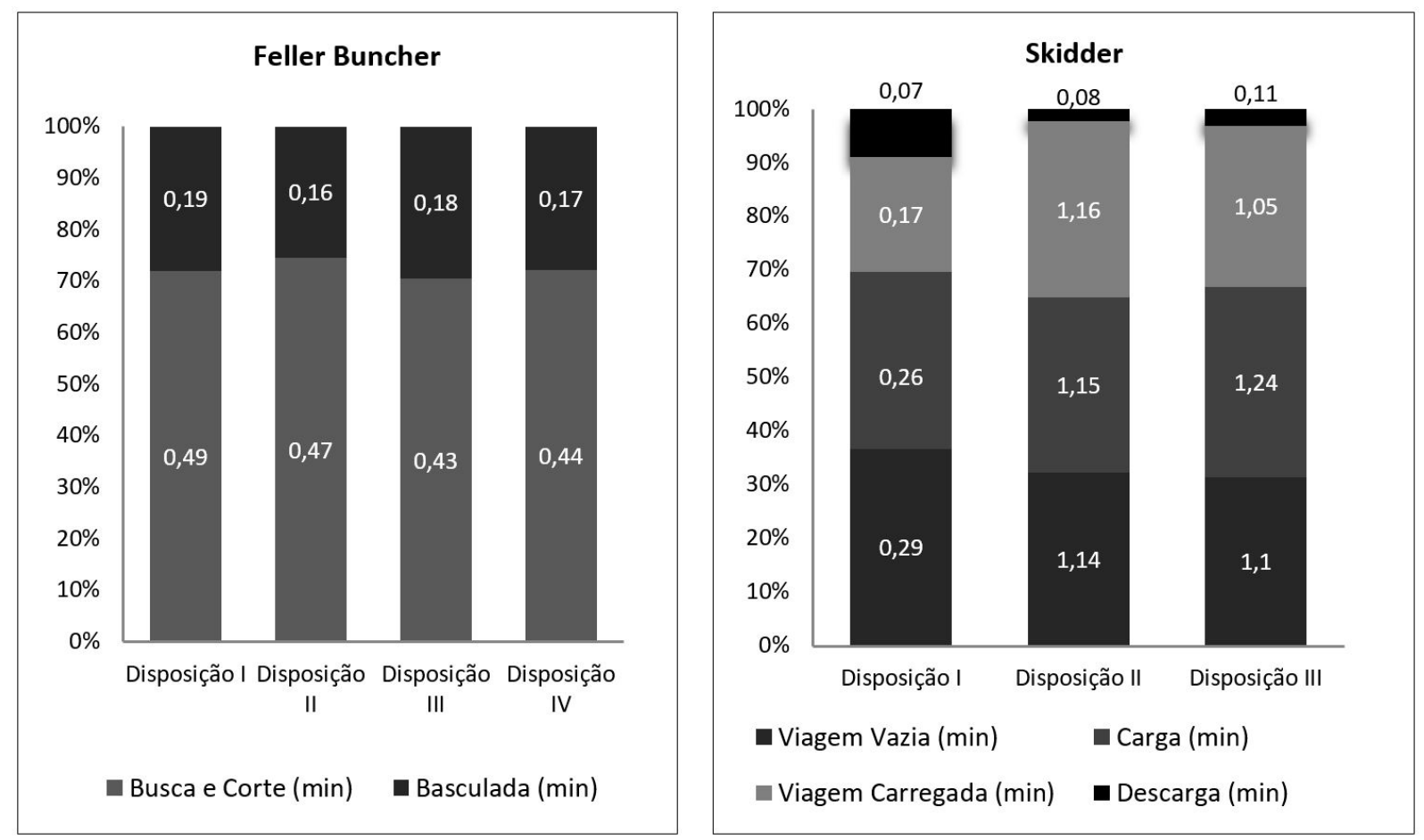

Figura 3. Elementos do ciclo operacional do feller buncher (a) e do skidder (b).

Figure 3. Productive cycle elements of feller-buncher (a) and skidder (b).

em relevo variando de plano a suave ondulado e por Santos et al. (2013a) analisando a produtividade e os custos de extração de um clambunk skidder.

Por outro lado, Minette et al. (2008) observaram para o skidder que a atividade "viagem carregada" e "viagem vazia" foram as operações que mais consumiram tempo do ciclo operacional. Fato que também foi observado na DI onde $37 \%$ do tempo produtivo foi gasto com a "viagem vazia". No entanto, cabe evidenciar que, como o skidder trabalhava com apenas um feixe por viagem, o tempo necessário para a "carga" foi menor e consequentemente aumentou a proporção dos outros elementos do ciclo.

Em relação ao tempo não produtivo do feller buncher, é importante destacar uma grande incidência de "trabalho complementar" (TC). Essa interferência do tempo produtivo foi causada principalmente pela necessidade, em alguns casos, de arrumar os feixes de árvores e pegar árvores que eventualmente caíram fora do feixe. O TC representou 5,24\%, 2,23\%, 3,73\%, 2,86\% do tempo total observado, respectivamente, nas DI, DII, DII e DIV. Também cabe salientar a grande influência do "deslocamento" (DE) do feller buncher na DI. Necessário para um melhor posicionamento e reposicionamento no trabalho do feller buncher. Tanto o TC quando o DE reiteram e ressaltam as dificuldades do operador do feller buncher em trabalhar na DI.

\section{Análises da produtividade e custos}

As análises de regressão (Tabela 5) evidenciaram a correlação positiva entre o tempo produtivo do feller buncher (Tfell) com o número de árvores por ciclo (narv) e com o ângulo de giro da máquina (ang), resultando no seguinte modelo: Tfell $=0,47+0,02 * n a r v+0,01 *$ ang. Já para o skidder, as análises de regressão evidenciaram uma correlação positiva entre o tempo total do ciclo (Tskd) com a variável distância de extração (dext) e o número de árvores por ciclo (narv) e uma correlação negativa com a velocidade de operação (vel), resultando no seguinte modelo: Tskd=1,86+0,02*dext+0,03*narv-0,30vel.

Primeiramente considerando o tempo produtivo do feller buncher, baseado nos modelos de regressão e nas angulações avaliadas (de $45^{\circ}$ a $180^{\circ}$ ), a produtividade variou de $48,30 \mathrm{~m}^{3} \mathrm{~h}^{-1}$ a $105,70 \mathrm{~m}^{3} \mathrm{~h}^{-1}$ e com respectivos custos de produção variando de 1,80 USD m a 3,90 USD m³ (Figura 4).

O maior custo de produção do feller buncher $\left(3,90 \mathrm{USD} \mathrm{m}^{-3}\right)$ foi observado justamente na DI que na prática representa apenas $12 \%$ do volume total produzido. Todavia, foi uma disposição necessária à abertura do eito e ao início da operação. Por outro lado, o menor custo de produção foi observado na DIII $\left(1,80 \mathrm{USD} \mathrm{m}^{-3}\right)$, consequência do menor giro da máquina $\left(45^{\circ}\right)$. A DIII $\left(45^{\circ}\right)$ comparada com a DII $\left(90^{\circ}\right)$ permitiu um ganho de produtividade em torno de $30 \mathrm{~m}^{3} \mathrm{~h}^{-1}$ e uma redução de 
Tabela 5. Modelo de regressão linear para o ciclo total do feller buncher e do skidder avaliados

Table 5. Linear regressionn model for the total feller-buncher and skidder cycle evaluated

\begin{tabular}{|c|c|c|c|c|c|c|c|c|c|}
\hline \multirow{2}{*}{ Modelo } & \multirow{2}{*}{$\begin{array}{c}\text { Variável } \\
\text { dependente }\end{array}$} & \multirow{2}{*}{$\mathbf{R}^{2}$} & \multicolumn{2}{|c|}{ Teste F } & \multirow{2}{*}{$\begin{array}{c}\text { Variável } \\
\text { independente }\end{array}$} & \multirow{2}{*}{ Coeficiente } & \multirow{2}{*}{$\begin{array}{c}\text { Erro } \\
\text { estimado }\end{array}$} & \multicolumn{2}{|c|}{ Teste T } \\
\hline & & & Valor $\mathrm{F}$ & $p$ & & & & Valor $\mathrm{t}$ & $p$ \\
\hline \multirow[t]{3}{*}{ Feller } & TFell & 0,03 & 13,96 & $<0,001$ & const. & 0,476 & 0,040 & 11,766 & $<0,001$ \\
\hline & & & & & narv & 0,021 & 0,007 & 2,817 & 0,005 \\
\hline & & & & & ang & 0,010 & 0,000 & 3,705 & $<0,001$ \\
\hline \multirow[t]{4}{*}{ Skidder } & TSkd & 0,87 & 741,65 & $<0,001$ & const. & 1,860 & 0,280 & 6,730 & $<0,001$ \\
\hline & & & & & dext & 0,020 & 0,000 & 29,910 & $<0,001$ \\
\hline & & & & & narv & 0,030 & 0,000 & 7,740 & $<0,001$ \\
\hline & & & & & vel & $-0,300$ & 0,040 & $-7,160$ & $<0,001$ \\
\hline
\end{tabular}

Onde:Tfell = tempo produtivo do feller buncher; Tskid = tempo produtivo do skidder; narv= árvores por ciclo; ang = ângulo do giro da máquina; dext $=$ distância de extração, vel = velocidade de operação do skidder.

\section{Feller Buncher}

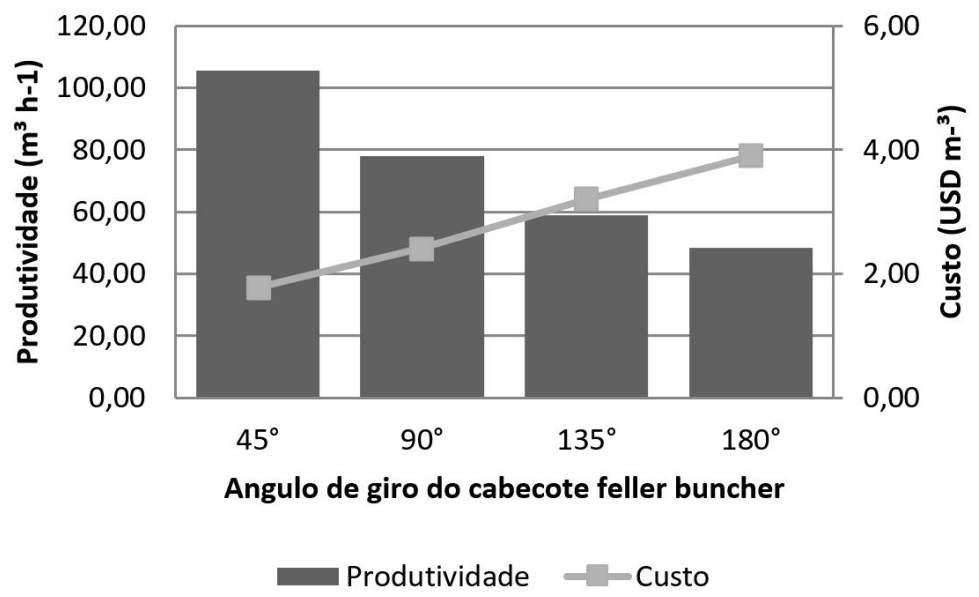

Figura 4. Produtividade e custos do feller buncher em relação ao ângulo de derrubada.

Figure 4. Costs and productivity of the feller-buncher relative to the angle of felling.

custos em torno de 25\%. Desta forma a DIII é a disposição que apresenta as maiores vantagens para a operação do feller buncher, em termos de produtividade e custos operacionais. Nascimento et al. (2011) também descreveram a derrubada em $45^{\circ}$ como sendo a mais vantajosa para o feller buncher em colheita de eucalipto.

Entretanto, cabe destacar que sempre que o feller buncher iniciava o eito com a DIII $\left(45^{\circ}\right)$, obrigatoriamente a segunda metade do eito era realizada a DIV $\left(135^{\circ}\right)$ de modo a viabilizar o arraste por ambas as estradas (A e B). Desta forma, comparando os custos de produção da DII (2,40 USD m³

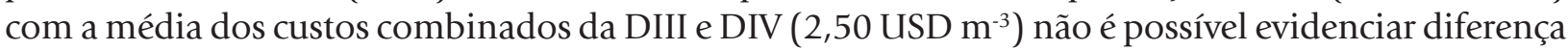
entre o feller buncher trabalhar em $90^{\circ}$ (DII) ou em uma combinação de $45^{\circ}$ (DIII) e $135^{\circ}$ (DIV).

Além disso, seria recomendável avaliar a interferência de outros fatores não considerados nesse estudo, como volume médio por árvore (VMI) ou a declividade do terreno. De acordo com Fiedler et al. (2008), Pereira et al. (2015) e Simões et al. (2010a), o VMI é a variável que mais afeta a produtividade do feller buncher.

Nos modelos de regressão do skidder não foi encontrado correlação entre o tempo produtivo com a variação das angulações dos feixes no interior do talhão, indicando que não existiu diferença entre o skidder trabalhar na DII ou DIII. Assim sendo, o tempo produtivo do skidder, foi estimado em função da distância de extração, do número de árvores por feixe e da velocidade (Figura 5). Lopes e Diniz (2015), Lopes et al. (2009, 2011); Santos et al. (2013a) também relacionaram a distância de extração como variável de influência na produtividade do skidder.

Considerando a distância média de extração em 125 m e uma média de 30 árvores por ciclo, a produtividade do skidder variou entre $181,9 \mathrm{~m}^{3} \mathrm{~h}^{-1}$, quando operado a $5 \mathrm{Km} \mathrm{h}^{-1}$ e $216,5 \mathrm{~m}^{3} \mathrm{~h}^{-1}$, quando a velocidade foi de $7 \mathrm{Km} \mathrm{h}^{-1}$ e com respectivos custos de produção de 0,75 USD m ${ }^{-3}$ e 0,63 USD m ${ }^{-3}$. Fiedler et al. (2008), analisando um skidder em um terreno plano e em uma floresta de eucalipto, 


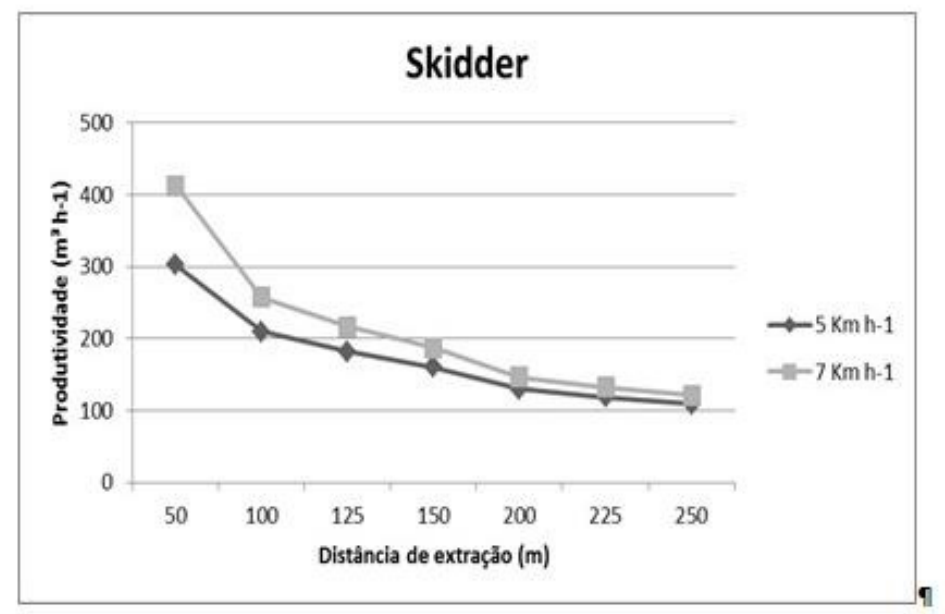

Figura 5: Produtividade média $\left(\mathrm{m}^{3} \mathrm{~h}^{-1}\right)$ segundo os centros de classes das distâncias de extração.

Figure 5. Mean productivity $\left(\mathrm{m}^{3} \mathrm{~h}^{-1}\right)$ according to the class centers of the extraction distances

encontraram uma produtividade de $42,3 \mathrm{~m}^{3} \mathrm{~h}^{-1}$ para uma distância média de $230 \mathrm{~m}$, enquanto que Santos et al. (2013a), analisando um clambunk skidder determinaram uma produtividade de $80,3 \mathrm{~m}^{3} \mathrm{~h}^{-1}$ para uma distância média de $241,2 \mathrm{~m}$ em um plantio de eucalipto. Valores inferiores dos encontrados por este estudo que considerando uma distância de $235 \mathrm{~m}$ seria em torno de $114 \mathrm{~m}^{3} \mathrm{~h}^{-1}$ e $127 \mathrm{~m}^{3} \mathrm{~h}^{-1}$ respectivamente para a velocidade de $5 \mathrm{Km} \mathrm{h}^{-1}$ e $7 \mathrm{Km} \mathrm{h}^{-1}$. Nenhum dos autores citados anteriormente relacionou a produtividade do skidder com a velocidade, o número de árvores por ciclo ou a angulação dos feixes no interior do talhão.

De modo geral, foi possível observar que a produtividade do skidder decresce à medida que se aumenta as distâncias de extração. Fato que também foi constatado por Lopes e Diniz (2015), Lopes et al. (2009, 2011) e Santos et al.(2013a). Além disso, em todas as classes de distância de extração a produtividade do skidder operando a $7 \mathrm{~km} \mathrm{~h}^{-1}$ foi superior quando comparado à produtividade do skidder operando a $5 \mathrm{~km} \mathrm{~h}^{-1}$. Entretanto, a diferença de produtividade entre as velocidades de $5 \mathrm{~km} \mathrm{~h}^{-1}$ e $7 \mathrm{~km} \mathrm{~h}^{-1}$ diminuiu à medida que aumentava a distância de extração. Fato que pode indicar que maiores distâncias de extração tendem a ser menos sucessíveis a variação de velocidade do skidder do que distâncias mais curtas.

\section{CONCLUSÕES}

A produtividade do feller buncher foi influenciada pelo ângulo de giro do cabeçote e pelo número de árvores por ciclo. Por conseguinte, a disposição DIII, quando o feller buncher operava a $45^{\circ}$, foi a que apresentou as maiores produtividades e menores custos de operação. Entretanto, visando o arraste para os dois lados do talhão não foram evidenciados diferença na produtividade e custos da operação entre a DII $\left(90^{\circ}\right)$ e a combinação da DIII $\left(45^{\circ}\right)$ com a DIV $\left(135^{\circ}\right)$. A disposição dos feixes também não apresentou diferença significativa na produtividade e custos do skidder. Contudo, a produtividade e custos do skidder foram influenciados pela distância de arraste, número de árvores por ciclo e velocidade de operação.

Recomenda-se o estudo de outras variáveis como VMI e diferentes inclinações de terreno, sobre a influência da angulação na produtividade e custos do feller buncher e do skidder.

\section{REFERÊNCIAS BIBLIOGRÁFICAS}

ACKERMAN, P.; BELBO, H.; ELIASSON, L.; JONG, A.; LAZDINS, A.; LYONS, J. The cost model for calculation of forest operations costs. International Journal of Forest Engineering, v. 25, n. 1, p. 75-81, 2014.

ALVARES, C. A.; STAPE, J. L.; SENTELHAS, P. C.; GONÇALVES, J. L. M.; SPAROVEK, G. Koppen`s climate classification map for Brazil. Meteorologishe Zeitschrift, Stuttgart, v. 22, n. 6, p. 711-728, 2014. 
ANAYA.H.; CRISTHIANSEN.P. Aprovechamiento forestall, análisis de apeo y transporte. San José. IICA, 1986.

BJÖRHEDEN, R.; THOMPSON, M. A. An international nomenclature for forest work study. In: FIELD D.B (Ed). PROCEEDINGS OF IUfRO. 20., 1995, Tampere Finland. Proceedings... Orono: University of Maine, 2000. p.190-215.

BRAMUCCI, M.; SEIXAS, F. Determinação e quantificação de fatores de influencia sobre a produtividade de "harvesters" na colheita florestal. Scientia Forestalis, Piracicaba, n. 62, p. 62-74, 2002.

FERNANDES, H. C.; LOPES, S. E.; TEIXEIRA, M. M.; MINETTE, L. J, RINALDI, P. C. N,; BERNARDES, A. M. Avaliação das características técnica e econômica de um sistema de colheita florestal de árvores inteiras. Scientia Forestalis, Piracicaba, v. 37, n. 83, p. 225-232, 2009.

FIEDLER, N. C.; ROCHA, E. B.; LOPES, E. S. Análise da produtividade de um sistema de colheita de árvores inteiras no norte do estado de Goiás. Floresta, Curitiba, v. 38, n. 4, p. 577-586, 2008.

IBA - INDÚSTRIA BRASILEIRA DE ÁRVORES. Relatório Anual 2016: ano base 2015. Brasília: IBA, 2016. 100 p. Disponível em: < iba.org/images/shared/Biblioteca/IBA_RelatorioAnual2016_.pdf.> Acesso em: 15 Nov. 2017.

LOPES, E. S.; DINIZ, C. C. C. Produtividade do trator florestal chockerskidder na extração de madeira em terrenos declivosos. Floresta, Curitiba, v. 45, n. 3, p. 625-634, 2015.

LOPES, E. S.; OLIVEIRA, D.; SAMPIETRO, J. A. Influence of wheeled types of a skidder on productivity and cost of the forest harvesting. Floresta, Curitiba, v.44, n.1, p. 53-62, 2014.

LOPES, E. S.; RODRIGUES, C. K.; CARMO, F. C.; FIEDLER, N. C.; OLIVEIRA, D. Avaliação técnica e de custos de um sistema de cabos aéreos na extração de Pinus taeda L. em região montanhosa. Scientia Forestalis, Piracicaba, v. 39, n. 91, p. 387-394, 2011.

LOPES, S.E.; FERNANDES, H.C.; MINETTE, L.J; SILVEIRA, J.C.M.; RINALDI, P.C.N. Avaliação técnica e econômica de um skidder operando em diferentes produtividades e distâncias de extração. Ciência agrotecnologia, Lavras, v. 33, n. 6, p. 1621-1626, 2009.

MACHADO, C.C. Colheita florestal. 3 ed. Viçosa: Editora UFV, 2014. 501 p.

MALINOVSKI, R, A; MALINOVISKI, J. R., Evolução dos sistemas de colheita de Pinus na região sul do Brasil. Curitiba: FUPEF, 1998. 138 p.

MAGAGNOTTI, N.; SPINELLI, R. Good practice guidelines for biomass production studies. Sesto Fiorentino: CNRIvalsa, 2012. 54 p.

MINETTE, L. J.; SILVA, E. N.; FREITAS, K. E.; SOUZA, A. P.; SILVA. E. P. Análise técnica e econômica da colheita florestal mecanizada em Niquelândia, Goiás. Revista Brasileira de Engenharia Agrícola e Ambiental, Campina Grande, v. 12, n. 6, p. 659-665, 2008.

NASCIMENTO, A. C.; LEITE, A. M. P.; SOARES, T. S.; FREITAS, L. C. Avaliação técnica e econômica da colheita florestal com feller buncher. Cerne, Lavras, v. 17, n. 1, p. 9-15, 2011.

OLIVEIRA, D.; LOPES, E.S.; FIEDLER, N.C. Avaliação técnica e econômica do forwarder na extração de tora de pinus. Scientia Forestalis, Piracicaba, v.37, n.84, p.525-533, 2009.

OLIVEIRA JUNIOR, E. D.; SEIXAS, F; BATISTA, J. L. F. Produtividade de Feller-Buncher em povoamento de eucalipto em relevo acidentado. Floresta. Curitiba, v. 39, n. 4, p. 905-912, 2009.

PEREIRA, A. L. N.; LOPES, E. S.; DIAS, A. N. Análise técnica e de custo do fellerbuncher e skidder na colheita de madeira em diferentes produtividades do povoamento. Ciência Florestal, Santa Maria, v. 25, n. 4, p. 981 989, 2015.

ROCHA, E. B.; FIEDLER, N. C.; ALVES, R. T.; LOPES, E. S.; GUIMARÃES, P. P.; PERONI, L. Produtividade e custos de um sistema de colheita de árvores inteiras. Cerne, Lavras, v. 15, n. 3, p. 372-381, 2009.

SANTOS, P. H. A.; SOUZA, A. P.; MARZANO, F. L. C.; MINETTE, L. J. Produtividade e custos de extração de madeira de eucalipto. Revista Árvore, Viçosa, v. 37, n. 3, p. 511-518, 2013a. 
Miyajima et al. - Influência da disposição dos feixes de árvores em diferentes

angulações na produtividade e custos de um sistema de árvores inteiras

SANTOS, H. G.; ALMEIDA, J. A.; OlIVEIRA, J. B.; LUMBRERAS, J. F.; ANJOS, L. H. C.; COELHO, M. R.; JACOMINE, P. K. T.; CUNHA, T. J. F.; OLIVEIRA, V. A. Sistema brasileiro de classificação de solos. 3.ed. Brasília: EMBRAPA, 2013b. 353 p.

SIMÕES, D.; FENNER, P. T.; ESPERANCINI, M. S. T. Produtividade e custos do fellerbuncher e Processador Florestal em povoamentos de eucalipto de primeiro corte. Ciência Florestal, Santa Maria, v. 24, n. 3, p. 621630, 2014.

SIMÕES, D.; IAMONTI, I. C., FENNER, P. T. Avaliação técnica e econômica do corte de eucalipto com fellerbuncher em diferentes condições operacionais. Ciência Florestal. Santa Maria, v. 20, n. 4, p.649-656, 2010 a.

SIMÕES, D.; FENNER, P. T.; ESPERANCINI, M. S. T. Avaliação técnica e econômica da colheita de florestas de eucalipto com harvester. Scientia Forestalis, Piracicaba, v. 38, n. 88, p. 611-618, 2010 b.

Recebido em: 19/07/2018

Aceito em: 01/03/2019 